\title{
Repensar la economía y la sociedad postpandemia. Desafíos públicos y privados
}

\section{Rethinking the post-pandemic economy and society. Public and private challenges}

\author{
Andrea Lluch * \\ CONICET-UNIVERSIDAD NACIONAL DE LA PAMPA \\ ASOCIACIÓN ARGENTINA DE HISTORIA ECONÓMICA
}

\section{RESUMEN:}

Hablamos de un mundo sin COVID-19, cuando realmente de lo que se trata es de un punto de quiebre. Hay muchos discursos que están hablando de que estamos en un cambio de época más que una época de cambios; otros están hablando de que estamos en una aceleración de la historia o que se trata de un shock de una envergadura desconocida en la historia reciente.

Palabras clave: Pandemia, Estado empresario, globalización, innovación, política pública

\section{AbSTRACT:}

We are talking about a world without COVID-19, when what is really at stake is a breaking point. There are many discourses that are talking about that we are in a time of change rather than a time of change; others are talking about that we are in an acceleration of history or that it is a shock of an unknown magnitude in recent history. Keywords: Pandemic, Entrepreneur state, globalization, innovation, public polic

*andrealluch@gmail.com 
uando fui convocada a participar de este webinar con el titulo “(Re)Pensar la Economía y Sociedad Post Pandemia” confieso que me intimidó un poco la invitación. En esa tónica, sumaré algunas reflexiones a este panel, sin ánimos de ser exhaustiva ni original. Como a muchos, el gran cúmulo de datos e información (y desinformación), así como las múltiples voces disonantes sobre esta coyuntura, ha llegado a agobiarme; al punto que la OMS ha caracterizado a esta situación como una "infodemia masiva”. Esta sensación, además, se ve agudizado por la extrema digitalización de nuestras vidas. Como reacción a esta situación "de miedo escénico" para hablar de la economía y sociedad post pandemia, buceé en algunas temáticas que vengo enseñando a nivel de posgrado. Por lo tanto, estas reflexiones intentan trazar líneas de diálogo con el estudio de la evolución del capitalismo en América Latina y repensar la globalización en el siglo XXI. Quisiera organizar mi presentación en base a algunas preguntas planteadas a modo de disparador del debate que seguirá.

\section{¿QUÉ HAY EN EL NOMBRE?}

Una de las cosas que me ha llamado la atención es qué hay en el nombre o qué hay detrás del nombre, o como comienzan a plantearse algunas preguntas. ¿Podemos hablar ya de Post Pandemia? ¿Habrá un mundo sin COVID-19? ¿Es un punto de quiebre? Algunos expertos hablan de que estamos ante un cambio de época más que en una época de cambios. Otros que estamos ante la "aceleración de la historia". O que se trata de "un shock para la opinión pública de una envergadura desconocida en la historia reciente. ${ }^{2}$

Como historiadora, creo que aun necesitamos más retrospectiva para poder conocer el alcance y la magnitud real de lo que estamos atravesando. E incluso para encontrar comparaciones y poder responder a preguntas tales como ¿Es distinta?, ¿Es parecida a qué y en qué? Entiendo que la búsqueda incesante de etiquetas es un reflejo del alto grado de ansiedad en que vivimos. Es decir, son búsquedas motivadas por el alto nivel de incertidumbre que nos rodea. Y de allí también que se hayan disparado distintas 
visiones, desde futuros de sociedades distópicas a otros discursos más positivos, incluso que llegan a plantear que el COVID-19 desaparecerá rápidamente, y que no será recordada como una gran crisis. En estas búsquedas y explicaciones contradictorias se asoma lo que algunos autores consideran como un rasgo de crisis extremas: en éstas, la discontinuidad domina, la linealidad se disuelve. Y ante ello, la predicción se vuelve esencial e imposible, y los modelos previamente validados se revelan muy alejados de las realidades que pretenden describir, y lo que queda es una gestión pragmática de la crisis a corto plazo. ${ }^{3}$

\section{¿FUE INESPERADA?}

Sin quitar importancia a otros acontecimientos relevantes pasados (guerras y migraciones) o actuales (como el cambio climático), lo especial de la pandemia fue su carácter inesperado. En la evaluación de las amenazas mundiales por parte de la inteligencia de los Estados Unidos para el año 2019 -última publicación antes de la pandemia de coronavirus- no se incluyó prácticamente ningún debate sobre los peligros de la pandemia (Coats, 2019: 21). Pero mi pregunta no es capciosa, y uno podría plantear que ya había una serie de condiciones previas. Por lo cual, me parece que esta crisis exige a pensar desde el pasado y presente, y no solamente concentrarse en escenarios futuros.

En particular, como han manifestado otras voces, es posible pensar esta crisis como un indicador de defectos de un orden social preexistente: la emergencia climática, la creciente desconexión entre humanos y el medioambiente, y el gran debate de la desigualdad. Al respecto, como han señalado varios economistas, y en particular en una reciente contribución Jeffrey Sachs: la alta desigualdad de ingresos es un flagelo desde muchos puntos de vista, pero en este contexto, conduce a peores condiciones sanitarias, lo que aumenta de manera significativa la vulnerabilidad a las muertes por COVID-19. ${ }^{4}$ Más desigualdad también significa que más gente viva en condiciones de hacinamiento $y$, por lo tanto, no pueda protegerse de manera segura. Con excepción de unos pocos lugares, toda América Latina 
esta siendo afectada duramente, y casi todo el hemisferio occidental comparte un legado de desigualdad masiva y de discriminación racial generalizada. ${ }^{5}$ Ello coexiste con un $40 \%$ a un $60 \%$ de informalidad. La mayoría de los trabajadores y las trabajadoras de bajos ingresos han debido seguir adelante, aún a riesgo de infectarse. Y su vez, las mujeres y otros sectores vulnerables están siendo más afectados. Es decir, América Latina llegó a esta coyuntura atravesada por un legado histórico de desigualdad, y otras problemáticas sociales. Así, la pandemia está ampliando desigualdades que ya existían, y por eso, no solamente es un problema médico, sino que es un problema económico y social.

\section{ES POSIBLE SABER ¿QUÉ SIGUE?}

La pregunta que nos convocaba es saber qué sigue. Si bien no hay forma de saber exactamente cuál será el daño económico provocado por la pandemia mundial del COVID-19, hay un acuerdo generalizado entre los economistas de que tendrá graves repercusiones negativas. El estamento de la ONU de ayer fue claro: "La pandemia COVID-19, y la recesión global que ha desencadenado, están por supuesto causando un inmenso sufrimiento humano en todo el mundo. Los que más sufren serán los menos preparados para responder. La pobreza extrema y el hambre van a aumentar drásticamente, los sistemas de atención de la salud de muchos países ya están en un punto de inflexión y una generación de niños está perdiendo su educación". ${ }^{6}$

Por lo tanto, la ONU está planteando que salvo que se tomen algunas medidas específicas se esperan años de crecimiento económico deprimido o interrumpido. Se está hablando de una crisis de desarrollo, una crisis de financiamiento para América Latina. Es la deuda un tema esencial; otros países tienen otras capacidades financieras para hacerse cargo del gasto público. Una potencial crisis de la deuda enfrentará a las llamadas elecciones imposibles: entre el servicio de la deuda y la protección de comunidades vulnerables en la lucha contra la pandemia. 
Por eso es importante ampliar el horizonte temporal. No sabemos cuándo va a terminar esta crisis. No sabemos cuando ni como terminará. Hoy se publicó una nota de Stiglitz quien confirma que, al principio de la crisis, casi todos anticipaban una recuperación rápida en forma de V. Pero estamos en julio del 2020, y la recuperación en forma de $\mathrm{V}$ es inverosímil. El Fondo Monetario Internacional prevé que, a fines de 2021, la economía mundial apenas habrá crecido respecto de fines de 2019, y que las economías de Estados Unidos y Europa se habrán achicado alrededor del 4\%. Se espera pérdidas de trabajo y quiebras, y se está señalando cómo cambiarán las pautas de producción y de consumo y los impactos que esto tendrá a futuro.

\section{¿QuÉ ES LO GLOBAL EN LO GLOBAL?}

¿Que pasa cuando ponemos la perspectiva en largo plazo y cuando pensamos los impactos de globalización y desglobalización? Ya en el 2008 vimos una interrupción de la integración global. ¿¿Hay algo que podemos vincular entre ambos procesos? Sabemos que son las políticas y no las tecnologías las que han generado estos shocks de creación y destrucción. Sabemos también que mientras la tecnología reduce las distancias geográficas (que a su vez contribuyen a la globalización), no la hacen inevitable. También distintos estudios alertan de que los gobiernos pueden detener o ralentizar los procesos de globalización en tanto perciben (o sus votantes) que son "perdedores". Los impactos positivos de esta disrupciones o crisis, y si los hubiera, dependen de las respuestas de los gobiernos y también del rol de los de los empresarios y de otros líderes sociales. Por ello, es importante pensar estos temas desde nuestras realidades, con todas sus complejidades, con una historia de crisis económicas recurrentes, con conflictos armados, con corrupción, con una marcada desindustrialización e inestabilidad, y un alto grado de inequidad. Requeriremos de miradas más endógenas y que respeten y que conozcan las especificidades de nuestros países. Por ejemplo, el grado de informalidad, o qué tipo de fiscalidad se necesita en países con estas estructuras, o qué tipo de cobertura universal. 
A MOdO DE CIERRE

Mi punto es que debemos reconocer la complejidad; no hay destinos escritos, hay opciones y múltiples caminos. La gestión de la crisis plantea preguntas para las que todavía probablemente no tengamos respuestas, pero necesitaremos del Estado y las políticas públicas. La innovación implica la necesidad de pensar diferente. Pero necesitamos también de instituciones preexistentes y creo que ese es el gran debate que se viene. Si queremos ser innovadores, vamos a tener que pensar distintas soluciones. Hay que pensar en el cómo queremos que sea y en esta discusión la historia importa, los contextos importan. Y en América Latina cuando hablamos de legitimidad hablamos de que el descontento es alto e importa en una sociedad que enfrenta el desafío de la inclusividad.

Notas AL FINAL

${ }^{1}$ Verhttps://www.bbc.com/mundo/noticiasinternacional-52314527

2 Ver https://theconversation.com/crisis-pandemica-yaceleracion-de-la-historia-136171

3 Ver https://www.e-ir.info/2020/06/07/nature-plays-lastrealism-post-realism-post-pandemic/ y

$4 \quad$ Ver las reflexiones de Kate Pickett y Richard Wilkinson en The Spirit Level y The Inner Level,

Ver https:/www.project-syndicate.org/commentary/ inequality-fuels-covid19-mortality-by-jeffrey-d-sachs-2020-06/ spanish

6 Ver https://reliefweb.int/report/world/rebirth-globaleconomy-post-covid-19-will-require-concrete-radical-ideas-actionfinance

Fecha recepción: 2 de julio de 2020

Fecha aceptación: 20 de julio de 2020

Versión final: 28 de octubre de 2020 